\title{
Qualidade de mamão 'Formosa' produzido no RN e armazenado sob atmosfera passiva $^{1}$
}

\author{
Quality of 'Formosa' papaya produced at RN and storage under passive atmosphere
}

\author{
Paula Lidiane de Oliveira Fernandes ${ }^{2}$, Edna Maria Mendes Aroucha², Pahlevi Augusto de Souza ${ }^{3}$, Aline Ellen \\ Duarte de Sousa ${ }^{4 *}$ e Patrícia Liane de Oliveira Fernandes ${ }^{5}$
}

\begin{abstract}
Resumo - Este trabalho teve por objetivo avaliar o efeito da cera de carnaúba (Primax Wax) e filme plástico de polietileno de baixa densidade "X-tend" sobre a vida útil pós-colheita de mamão 'Formosa' (Tainung 1) produzido em Baraúna - RN. O experimento foi conduzido no laboratório de Pós-colheita da Universidade Federal Rural do Semi-Árido (UFERSA). Utilizou-se um esquema fatorial 3 x 6 com 3 repetições de três frutos por parcela, constituindo na combinação de 3 tipos de atmosferas (cera, filme de polietileno e controle) com 6 tempos de armazenamento $(0 ; 7 ; 14 ; 21 ; 28 ; 35)$. Os frutos dos distintos tratamentos foram armazenados em câmaras frias a $10 \pm 2{ }^{\circ} \mathrm{C}$ e UR $90 \pm 5 \%$, analisados em intervalos de sete dias. As características avaliadas foram: aparência externa, perda de massa, firmeza da polpa, sólidos solúveis, acidez titulável e vitamina C. Constatou-se ser o filme plástico o mais eficiente em manter a qualidade externa e reduzir a perda de massa dos frutos. A cera de carnaúba, na concentração utilizada, mostrou eficiência relativa na conservação de mamão quando comparada ao filme plástico. A vida útil pós-colheita dos frutos mantidos sob atmosfera modificada foi de 35 dias e do controle apenas 28 dias.
\end{abstract}

Palavras-chave - Carica papaya L. Alimentos-armazenamento. Fruta-conservação.

\begin{abstract}
The aim of this work was to evaluate the effect of carnauba wax (Primax Wax) and low-density polyethylene film "X-tend" on shelf life of 'Formosa' papaya fruits produced in Baraúna, RN. The experiment was carried out in the Postharvest Laboratory of the Universidade Federal Rural do Semi-Árido (UFERSA). A 3 x 6 factorial scheme with three replications of three fruits per plot in a completely randomized design was used. The treatments consisted of the combination of three types of atmosphere (wax, polyethylene film and control) with six storage times $(0 ; 7 ; 14 ; 21 ; 28$ and 35$)$. The fruits of these treatments were stored in cold chamber at $10 \pm 2{ }^{\circ} \mathrm{C}$ and $\mathrm{RH} 90 \pm 5 \%$, and analyzed in 7 days intervals. The evaluated traits were: external appearance, weight loss, pulp firmness, soluble solids, titratable acidity and $\mathrm{C}$ vitamin. It was observed that polyethylene film was the most efficient coverage to keep the external quality and to reduce the weight loss of the papaya fruits. The carnauba wax in the used concentration shows good efficiency in papaya fruits conservation as compared with that polyethylene film. The shelf life of papaya fruits kept under modified atmosphere was of 35 days and for those fruits kept at ambient condition was of 28 days.
\end{abstract}

Key words - Carica papaya L. Food-storage. Fruit-preservation.

\footnotetext{
* Autor para correspondência

${ }^{1}$ Recebido para publicação em 26/08/2009; aprovado em 10/10/2010

Monografia do primeiro autor apresentada ao Curso de Engenharia Agronômica, UFERSA

${ }^{2}$ Programa de Pós-Graduação em Fitotecnia/UFERSA, Mossoró-RN, Brasil, paula_esam@hotmail.com, aroucha@ufersa.edu.br

${ }^{3}$ Instituto Federal do Ceará, Campus de Limoeiro do Norte, Limoeiro do Norte-CE, Brasil, pahlevi@cefetce.br

${ }^{4}$ Programa de Pós-Graduação em Fisiologia Vegetal/UFV, Viçosa-MG, Brasil, 36.570-000, aline_esam@hotmail.com

${ }^{5}$ Departamento de Agrotecnologia e Ciências Sociais, DACS/UFERSA, Mossoró-RN, Brasil, patricia_liany@hotmail.com
} 


\section{Introdução}

O mamão (Carica papaya L.) é uma frutícola de grande expressão econômica, a área cultivada com mamoeiro tem aumentado bastante nos últimos anos. $\mathrm{O}$ Brasil é o maior produtor mundial de mamão, e o terceiro maior exportador da fruta, responde por cerca de $25 \%$ da produção mundial, com 1,6 milhões de toneladas por ano. O estado da Bahia é o maior produtor seguido do Espírito Santo, juntos são responsáveis por $86 \%$ da produção nacional. No Rio Grande do Norte a área plantada com mamão está em torno de 1.712 hectares, representando $8 \%$ da área plantada com mamão no nordeste (IBGE, 2007).

A produção nacional do mamão é composta basicamente por dois grupos: 'Formosa' e 'Havaí', sendo esse último comercializado tanto no mercado externo como no interno. O grupo 'Formosa', por sua vez, era destinado principalmente para o mercado interno (ROCHA, 2005), porém nos últimos anos vem apresentando tendência crescente para a exportação.

Omamão éum fruto climatérico cujas transformações resultantes do amadurecimento ocorrem rapidamente após a colheita do fruto fisiologicamente maturo e são desencadeadas pela produção do etileno e aumento da taxa respiratória. Isso o caracteriza como um fruto bastante perecível na fase pós-colheita (FONTES et al., 2008).

O controle de amadurecimento para esses produtos é de fundamental importância para o aumento da vida útil pós-colheita, principalmente quando visa a atender mercados mais distantes, tanto o interno quanto o externo (OLIVEIRA; VIANNI, 2004).

As condições ideais de armazenamento correspondem àquelas em que os produtos podem ser acondicionados, pelo maior espaço de tempo possível, sem perda apreciável de seus atributos de qualidade, como sabor, aroma, textura, cor e teor de umidade. (CHITARRA; CHITARRA, 2005).

Um aumento da vida útil de frutas pode ser obtido pelo uso de filmes plásticos flexíveis, que agem como embalagem de atmosfera modificada (AL-ATI; HOTCHKISS, 2003). Esta técnica utilizada como um suplemento da refrigeração promove o abaixamento da taxa de respiração pelo aumento do nível de $\mathrm{CO}_{2}$ e decréscimo do nível de $\mathrm{O}_{2}$ (RAI et al., 2002) além disso, minimiza a perda de água (CISNERO - ZEVALLOS; KROCHTA, 2002).

Dessa forma, o presente trabalho teve por objetivo avaliar o efeito da cera de carnaúba (Primax Wax) e filme plástico de polietileno de baixa densidade "X-tend" sobre a vida útil pós-colheita de mamão 'Formosa' produzido em Baraúna - RN.

\section{Material e métodos}

Os frutos de mamão 'Formosa' (Tainung 1), no estádio de maturação II (com até $25 \%$ de listras amarela), foram colhidos em um plantio comercial localizado no município de Baraúna-RN, no período de janeiro de 2007. O local apresenta clima semi-árido, temperatura média de $27,4{ }^{\circ} \mathrm{C}$, umidade relativa média de $68,9 \%$ com precipitação pluviométrica anual de $673 \mathrm{~mm}$ (INMET, 2010) e insolação diária de 10,9 h.

Logo após a colheita os frutos foram transportados em monoblocos para o Laboratório de Pós-Colheita da Universidade Federal Rural do Semi-árido (UFERSA), onde foi conduzido o experimento. Os tratamentos consistiram de imersão dos frutos em cera de carnaúba a $20 \%$, acondicionamento em embalagens de polietileno de baixa densidade (X-tend: 815 PP26) e controle. Em cada embalagem foram acondicionados cinco frutos. Em seguida, os frutos dos distintos tratamentos foram armazenados em câmaras frias reguladas a temperatura de $10{ }^{\circ} \mathrm{C} \pm 2{ }^{\circ} \mathrm{C}$, mantidas a $90 \pm 5 \%$ UR durante os intervalos de tempos de $7 ; 14 ; 21 ; 28$ e 35 dias.

As análises físicas e químicas para a avaliação da qualidade dos frutos durante o período de armazenamento foram as seguintes: Aparência externa - adotou-se uma escala subjetiva com notas variando de 1 a 5 , de acordo com a ausência ou presença de defeitos. Foram observados depressões, murchas ou ataque fúngico $(1=$ fruto extremamente deteriorado, $2=$ severo, $3=$ médio, $4=$ leve, $5=$ ausência de manchas, murcha ou depressões), foi considerado impróprio para o consumo, frutos com nota inferior ou igual a 3. Perda de massa - determinada pela diferença entre a massa no tempo inicial e aquela obtida em cada época, sendo expressa em porcentagem (\%). Firmeza da polpa: determinada utilizando-se penetrômetro manual, os resultados expressos em Newton $(\mathrm{N})$; Teor de sólidos solúveis: por meio de refratometria, de acordo com a (AOAC, 1992), utilizando-se refratômetro digital, sendo os resultados expressos em ${ }^{\circ}$ Brix; Acidez titulável: determinada segundo a técnica estabelecida pelo Instituto Adolfo LUTZ (1985) e os resultados foram expressos em porcentagem de ácido cítrico. Teor de vitamina C: determinada por titulometria e os resultados expressos em $\mathrm{mg}$ de ácido ascórbico/100g de polpa, conforme o método 43.064 descrito pela (AOAC, 1992).

O delineamento experimental foi o inteiramente aleatorizado, em esquema fatorial $3 \times 6$ (três tipos de atmosfera e seis tempos de armazenamento), com três repetições de três frutos por tratamento. Os dados foram submetidos à análise de variância e quando houve interação significativa procedeu-se à análise de regressão polinomial para o fator tempo (GOMES, 1987). 


\section{Resultados e discussão}

Houve interação significativa entre os fatores estudados (tipos de atmosferas $\mathrm{x}$ tempos) para as características aparência externa e interna, firmeza da polpa, perda de massa e acidez titulável (FIG. 1; 2; 3; 4 e 5). E efeito isolado do fator tipo de revestimento para a característica sólidos solúveis.

Observou-se uma redução na aparência externa dos frutos durante o armazenamento (FIG. 1). Desdobrando os tipos de atmosferas modificadas dentro de tempo de armazenamento, observou-se que o acondicionamento em filme plástico X-tend foi mais efetivo em relação ao uso de cera de carnaúba em manter a qualidade externa do fruto (FIG. 1). No entanto, verificou-se que ambos os tipos de atmosferas modificadas propiciaram boa aparência externa dos frutos por período maior de tempo (35 dias), em relação ao controle (28 dias). Resultados semelhantes foram detectados em mamão 'Formosa' por Solon et al. (2005) e em caju por Moura et al. (2005), os quais observaram que os pedúnculos envolvidos com filmes plásticos obtiveram melhores notas de aparência externa durante o período de armazenamento.

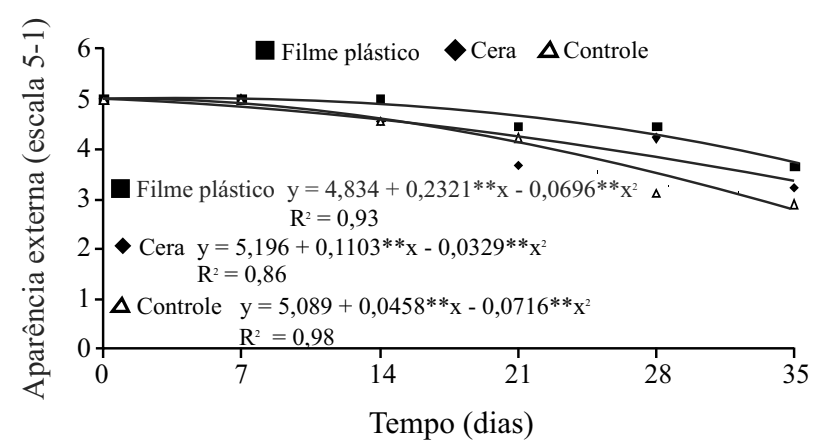

Figura 1 - Estimativa da aparência externa de frutos de mamão 'Formosa' (Tainung 1), cobertos com cera de carnaúba ou filme plástico X-tend durante 35 dias a $10{ }^{\circ} \mathrm{C} \pm 2{ }^{\circ} \mathrm{C}$ e $90 \pm 5 \%$ UR. UFERSA, Mossoró/RN, 2007

A avaliação da aparência do fruto é extremamente útil para estimar o tempo de comercialização, pois o produto deve chegar aos grandes centros consumidores com qualidade visual aceitável para o consumo e comercialização.

Houve aumento na perda de massa com o tempo de armazenamento em todos os tratamentos (FIG. 2). No entanto, verificou-se que a utilização do filme plástico X-tend propiciou menor redução da perda de massa dos frutos $(1,48 \%)$ quando comparados aos frutos revestidos com cera de carnaúba e controle em que as perdas de massa foram de $3,10 \%$ e $4,83 \%$, respectivamente, aos 35 dias de armazenamento.

De acordo com Sousa et al. (2000), as perdas de massa fresca em frutos armazenados ocorrem em decorrência da água eliminada por transpiração causada pela diferença de pressão de vapor entre o fruto e o ar no ambiente e dos processos metabólicos de respiração.

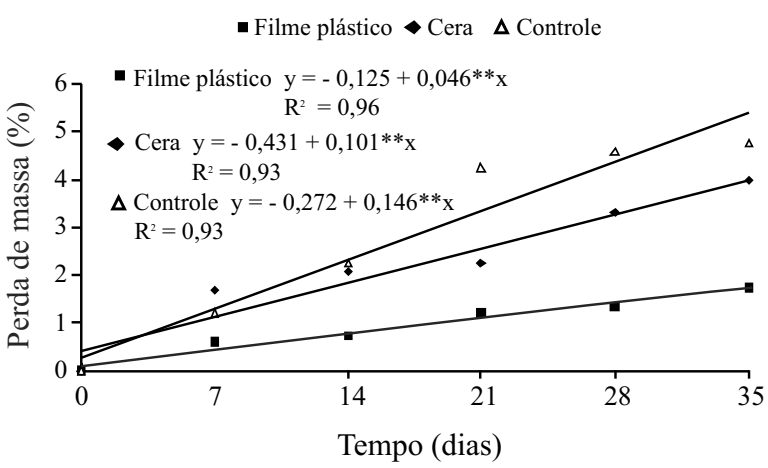

Figura 2 - Estimativa da perda de massa de frutos de mamão 'Formosa' (Tainung 1), cobertos com cera de carnaúba ou filme plástico X-tend durante 35 dias a $10{ }^{\circ} \mathrm{C} \pm 2{ }^{\circ} \mathrm{C}$ e $90 \pm 5 \%$ UR. UFERSA, Mossoró/RN, 2007

Verificou-se perda de firmeza da polpa durante o tempo de armazenamento dos frutos, independente do tratamento experimental (FIG. 3). Verificou-se que, os frutos revestidos com filme plástico e frutos-controle apresentaram amolecimento da polpa semelhante até aos 21 dias de conservação, sendo a perda acentuada, notadamente, dos frutos-controle após esse período. Aos 35 dias de armazenamento os frutos de mamão revestidos com filme plástico X-tend apresentaram perda de firmeza inferior $(18 \mathrm{~N})$ à cera de carnaúba $(16 \mathrm{~N})$ e controle $(13 \mathrm{~N})$. Para os tratamentos com atmosfera modificada, o filme plástico e a cera, o aumento na perda de firmeza foi retardado devido à barreira física ocasionada pelos revestimentos, que diminuem as trocas gasosas e reduzem a taxa respiratória dos frutos pela modificação da atmosfera (FIG. 3).

Dentre as causas principais da perda da firmeza da polpa do mamão, está a degradação de protopectina da lamela média e da parede celular primária, o aumento da pectina solúvel e a perda de açúcares neutros não-celulósicos (JACOMINO et al., 2002). Essas alterações bioquímicas resultam, provavelmente, de mudanças na atividade de enzimas hidrolíticas, 


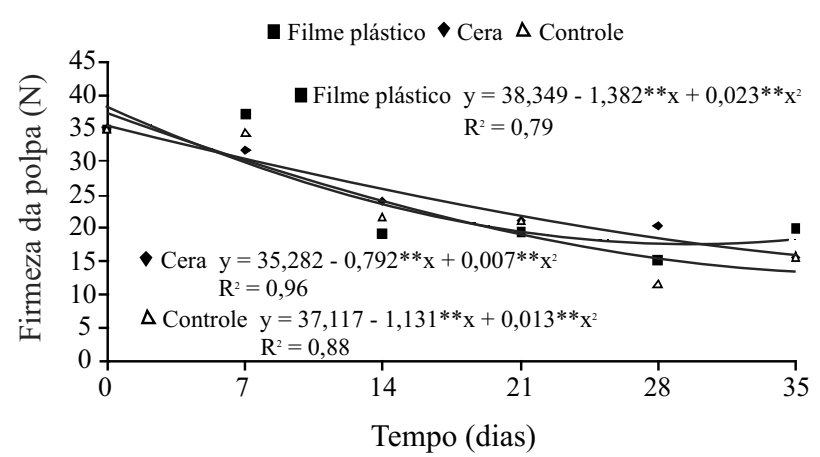

Figura 3 - Estimativa da firmeza da polpa de frutos de mamão 'Formosa' (Tainung 1), cobertos com cera de carnaúba ou filme plástico X-tend durante 35 dias a $10^{\circ} \mathrm{C} \pm 2{ }^{\circ} \mathrm{C}$ e $90 \pm 5 \%$ UR. UFERSA, Mossoró/RN, 2007

como as poligalacturonase, pectinametilesterase, $\beta$-galactosidase e celulases presentes nas células, juntamente com a perda de água (ABU-GOUKH; BASHIR, 2003; OWINO et al., 2004).

Observou-se redução no teor de sólidos solúveis da polpa durante o armazenamento (FIG. 4). Os menores valores de sólidos solúveis ocorreram a partir de 21 dias de conservação. Como o mamão é um fruto climatérico, a diminuição nos teores de sólidos solúveis, durante o armazenamento, pode estar associada ao possível processo oxidativo respiratório que culmina com o consumo de reservas (LIMA; DURIGAN, 2000).

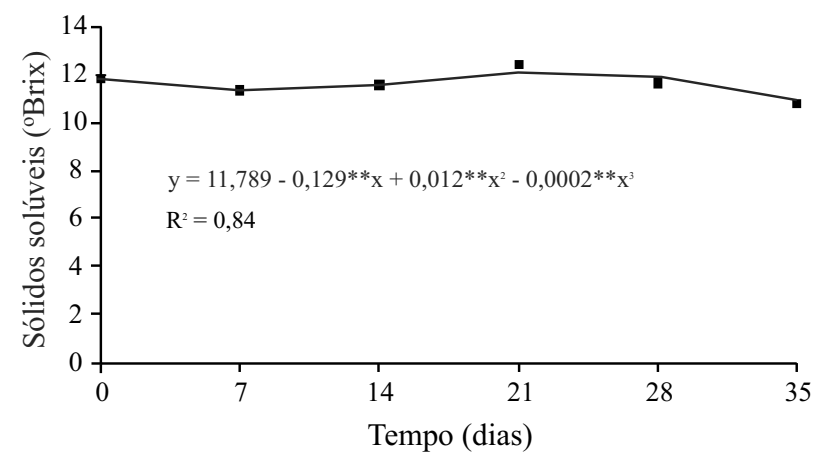

Figura 4 - Estimativa dos sólidos solúveis de frutos de mamão 'Formosa' (Tainung 1), armazenados durante 35 dias a $10{ }^{\circ} \mathrm{C} \pm$ $2{ }^{\circ} \mathrm{C}$ e $90 \pm 5 \%$ UR. UFERSA, Mossoró/RN, 2007

O teor de sólidos solúveis diferiu quanto ao tratamento. Os frutos tratados com cera de carnaúba mantiveram maiores teores de sólidos solúveis $\left(11,85^{\circ} \mathrm{Brix}\right)$ quando comparados ao uso de filme plástico ( $\left.11,37^{\circ} \mathrm{Brix}\right) \mathrm{e}$ foram semelhantes aos dos frutos-controle $\left(11,57^{\circ} \mathrm{Brix}\right)$.
O aumento de sólidos solúveis pode ter sido decorrente da transformação das reservas acumuladas durante a formação e o desenvolvimento desses sólidos em açúcares solúveis. (JERÔNIMO; KANESIRO, 2000). Uma vez que, o mamão não possui reservas de amido, portanto, não pode haver aumento nos teores de açúcares solúveis após a colheita dos frutos (QUEIROZ, 2009).

Verificou-se um aumento da acidez titulável dos frutos ao longo do período de armazenamento (FIG. 5), indicando uma possível síntese de ácidos orgânicos. O aumento da acidez dos frutos pode se atribuído à formação do ácido galacturônico no processo de degradação da parede celular, processos que ocorrem durante o amadurecimento do mamão, enfatizam Costa e Balbino (2002).

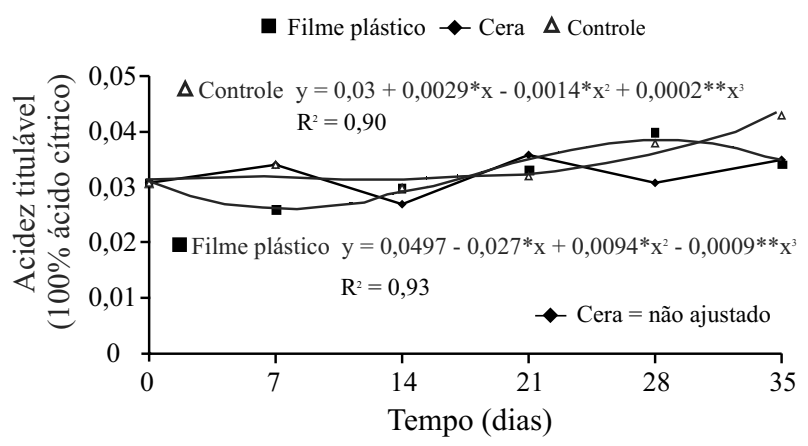

Figura 5 - Estimativa da acidez titulável de frutos de mamão 'Formosa' (Tainung 1), cobertos com cera de carnaúba ou filme plástico X-tend durante 35 dias a $10{ }^{\circ} \mathrm{C} \pm 2{ }^{\circ} \mathrm{C}$ e $90 \pm 5 \%$ UR. UFERSA, Mossoró/RN, 2007

Os valores de acidez dos frutos testemunha foram superiores aos detectados nos frutos revestidos com filme ou cera, aos 35 dias de armazenamento. Entretanto, ainda permaneceu dentro da faixa ideal para a comercialização (FAGUNDES; YAMANISHI, 2001).

Independente do tratamento verificou-se aumento da vitamina $\mathrm{C}$ até 21 dias de armazenamento (FIG. 6). E um ligeiro decréscimo nos valores após esse período. Em mamão, diferentemente do que ocorre na maioria dos frutos, verifica-se um aumento gradual nos teores de vitamina $\mathrm{C}$ até o completo amadurecimento do fruto (SELVARAJ et al., 1982).

O tipo de revestimento não afetou de forma significativa o teor de vitamina $\mathrm{C}$ dos frutos. Não se observaram elevadas perdas, dessa vitamina, no final do período de armazenamento. Os valores encontrados, no presente trabalho, estão próximos aos valores detectados em mamão Formosa, 76,7 $\pm 1,21 \mathrm{mg} 100 \mathrm{~g}^{-1}$, por Souza et al. (2005). 


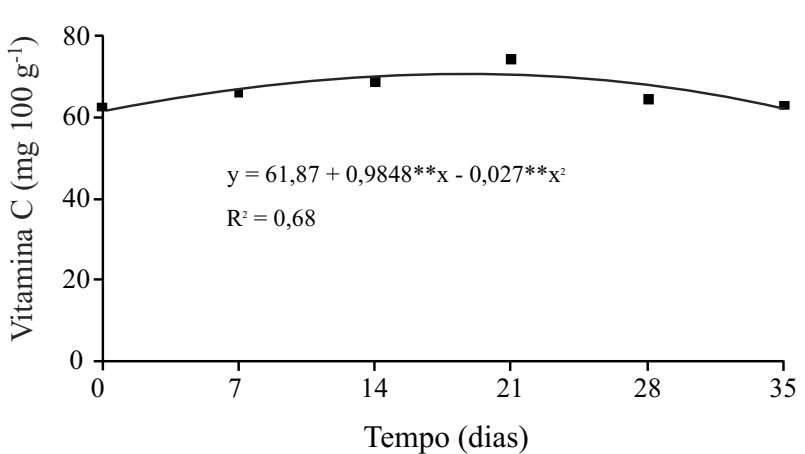

Figura 6 - Estimativa da vitamina $\mathrm{C}$ de frutos de mamão 'Formosa' (Tainung 1), cobertos com cera de carnaúba ou filme plástico X-tend durante 35 dias a $10{ }^{\circ} \mathrm{C} \pm 2{ }^{\circ} \mathrm{C}$ e $90 \pm 5 \%$ UR. UFERSA, Mossoró/RN, 2007

\section{Conclusões}

1. O uso do filme plástico foi eficiente em manter a qualidade externa e reduzir a perda de massa dos frutos durante o período de armazenamento;

2. A cera de carnaúba, na concentração utilizada, mostrou eficiência inferior à conservação de mamão quando comparada ao filme plástico;

3. A vida útil pós-colheita dos frutos mantidos sob atmosfera modificada foi de 35 dias e do controle apenas 28 dias.

\section{Referências}

ABU-GOUKH, A.; BASHIR, H. A. A. Changes in pectic enzymes and cellulase activity during guava fruit ripening. Food Chemistry, v. 83, n. 02. p. 213-218, 2003.

AL-ATI, T.; HOTCHKISS, J. H. The role of packaging film permeselectivity in modified atmosphere packaging. Journal of Agricultural and Food Chemistry, v. 51, n. 14, p. 41334138, 2003.

AOAC INTERNACIONAL. Official methods of analysis of the Association of Official Analytical Chemistry. 11 ed. Washington: AOAC, $1992.1115 \mathrm{p}$.

CHITARRA, M. I. F.; CHITARRA, A. B. Pós-colheita de frutas e hortaliças: fisiologia e manuseio. 2. ed. Lavras: ESAL/ FAEPE, 2005. 785 p.

CISNERO-ZEVALLOS, L.; KROCHTA, J. M. Internal modified atmosphere of coated fresh fruit and vegetables: Understanding relative humidity effects. Journal of Food Science, v. 67, n. 08, p. 2792-2797, 2002.

COSTA, A. F. S.; BALBINO, J. M. S. Características da fruta para exportação e normas de qualidade. In: FOLEGATTI, M. I. S.; MATSUURA, F. C. A. U. (Ed.). Mamão: pós-colheita. Brasília, DF: Embrapa Informação Tecnológica, 2002. p. 12-18. (Série Frutas do Brasil, 21).
FAGUNDES, G. R.; YAMANISHI, O. K. Características físicas e químicas de frutos de mamoeiro do grupo 'Solo' comercializados em quatro estabelecimentos de Brasília - DF. Revista Brasileira de Fruticultura, v. 23, n. 03, p. 541-545, 2001.

FONTES, R. V. et al. Atividade da pectinametilesterase e sua relação com a perda de firmeza da polpa de mamão cv. Sunrise Solo e Tainung 1. Revista Brasileira Fruticultura, v. 30, n. 01, p. 054-058, 2008.

GOMES, F. P. Curso de estatística experimental. Piracicaba: Nobel, 1987. 467 p.

INSTITUTO ADOLFO LUTZ. Normas analíticas, métodos químicos e físicos para análise de alimentos. 3. ed. São Paulo: Instituto Adolfo Lutz, 1985. 533 p. v. 1,

INSTITUTOBRASILEIRODEGEOGRAFIAEESTATÍSTICA (IBGE). Produção Agrícola Municipal, 2007. Disponível em: <www.ibge.gov.br>. Acesso em: 25 jan. 2009.

INSTITUTO NACIONAL DE METEREOLOGIA (INMET). 2010. Disponível em <www.inmet.gov.br>. Acesso em: 19 fev. 2010.

JACOMINO, A. P. et al. Amadurecimento do mamão com 1-metilciclopropeno. Scientia Agrícola, v. 59, n. 02, p. 303308. 2002.

JERONIMO, R. F.; KANESIRO, M. A. B. Efeito da associação de armazenamento sob refrigeração e atmosfera modificada na qualidade de mangas 'Palmer'. Revista Brasileira de Fruticultura, v. 22, n. 02, p. 237- 243, 2000.

LIMA, M. A.; DURIGAN, J. F. Conservação de goiaba 'Pedro Sato' associando-se refrigeração com diferentes embalagens plásticas. Revista Brasileira de Fruticultura, v. 22, n. 02, p. 232-236, 2000.

MOURA, C. F. H. et al. Aparência e cor da película de pedúnculos de clones de cajueiro anão precoce para consumo in natura armazenados sob diferentes camadas de PVC. Revista Ciência Agronômica, v. 36, n. 03, p. 371-375, 2005.

OLIVEIRA, J. R.; VIANNI, R. Efeito da aplicação do 1- MCP na pós-colheita do mamão 'Golden'. In: REUNIÃO DE PESQUISA DO FRUTIMAMÃO, 2, 2004, Anais... Campos de Goytacazes: UENF, 2004. p. 317-323.

OWINO, W. O. et al. Alterations in cell wall polysaccharides during ripening in distinct anatomical tissue regions of the fig (Ficus carica L.) fruit. Postharvest Biology and Technology, v. 32, n. 01, p. 67-77, 2004.

QUEIROZ, R. R. F. Desenvolvimento de mamão Formosa 'Tainung 01' cultivado em Russas-CE. 62 f. 2009. Dissertação (mestrado em Fitotecnia). Universidade Federal Rural do Semiárido, Mossoró-RN.

RAI, D. R. et al. Modified atmosphere packaging and its effect on quality and shelf-life of fruits and vegetables - An overview. Journal of Food Science and Technology, v. 39, n. 03, p. 199-207, 2002.

ROCHA, R. H. C. Qualidade do mamão 'Formosa' submetido a diferentes temperaturas de refrigeração. Revista Brasileira de Fruticultura, v. 27, n. 03, p. 386-389, 2005. 
SELVARAJ, Y. et al. Changes in the chemical composition of four cultivates of papaya during growth and development. Journal of Horticultural Science, v. 57, n. 01, p. 135-143, 1982.

SOLON, K. N. et al. Conservação pós-colheita do mamão formosa produzido no Vale do Assu sob atmosfera modificada. Caatinga, v. 18, n. 02, p. 105-111, 2005.
SOUSA, R. F. et al. Armazenamento de ciriguela (Spondia purpurea L.) sob atmosfera modificada e refrigeração. Revista Brasileira de Fruticultura, v. 22, n. 03, p. 334-338, 2000.

SOUZA B. S. et al. Conservação de mamão 'Formosa' minimamente processado armazenado sob refrigeração. Revista Brasileira de Fruticultura, v. 27, n. 2, p. 273-276, 2005. 